\title{
The Vertical-Tube Solar Collector: A Low-Cost Design Suitable for Temperate High-Latitude Locations
}

\author{
Luis Juanicó and Nicolás Di Lalla \\ Argentinian National Council of Researches (Conicet), Bariloche Atomic Center, 8400 Bariloche, Argentina \\ Correspondence should be addressed to Luis Juanicó; juanico@cab.cnea.gov.ar
}

Received 15 January 2014; Revised 14 June 2014; Accepted 15 June 2014; Published 3 July 2014

Academic Editor: Santanu Bandyopadhyay

Copyright @ 2014 L. Juanicó and N. Di Lalla. This is an open access article distributed under the Creative Commons Attribution License, which permits unrestricted use, distribution, and reproduction in any medium, provided the original work is properly cited.

\begin{abstract}
A new low-cost solar collector based on thick $\left(4.5^{\prime \prime}\right)$ vertical tubes related to the previous design based on long $1.5^{\prime \prime}$ plastic hoses connected directly between water-grid supply and consumption is presented. This novel design could noticeably improve its performance for temperate locations mid and high latitudes, as was demonstrated by dynamic thermal modeling. This tool has been useful for understanding the particular characteristics of this kind of water-pond collector and besides, for noticeably improving its performance by optimizing its parameters, like tube diameter and number of glazing layers. By this way, the optimized design could fully satisfy the household demand up to midnight along the whole year for Buenos Aires $\left(35^{\circ} \mathrm{S}\right)$ and during summers (remaining as a useful preheater for the whole year) for Ushuaia $\left(55^{\circ} \mathrm{S}\right)$. Besides, its high simplicity makes it available for user's own construction, costing down 50 dollars for a single-family unit.
\end{abstract}

\section{Introduction}

The demand of sanitary hot water in tropical developing countries can be supplied by locally manufactured cheap solar collectors, considering the low difference of temperature involved. Following this idea, many solar enthusiasts have often proposed hose-based solar collectors (e.g., by using a plastic hose coiled within a glazing box), but mostly they have achieved poor results $[1,2]$. However, the hose collector has been recently studied by dynamic thermal and hydraulic modeling, showing the huge potential of this concept. Their particular behaviors were discussed and therefore its performance was noticeably improved for tropical lowlatitude locations [3] and for temperate mid-latitude locations [4]. Although these studies have demonstrated that this collector is not suitable for cold high-latitude locations, they give us a good background for understanding their special characteristics, which is convenient to summarize here.

The simplest hose-based design consists in one long LDPE hose wrapped with several transparent layers of a lowcost plastic material (preferably bubble wrap made by LDPE transparent film) simply resting onto the roof, as is illustrated in Figure 1. Here, the hose is connected directly between water-grid supply and consumption, using the district-grid pressure as driven force for pumping hot water through the whole hose. The thermal-hydraulic modeling has shown that, by choosing a diameter between $1^{\prime \prime}$ and $2^{\prime \prime}$ of a $100 \mathrm{~m}$ in length hose, this system can provide the desired consumption flow together with a reasonable storage capacity (50 liters to 200 liters) and enough surface $\left(2.5 \mathrm{~m}^{2}\right.$ to $\left.5 \mathrm{~m}^{2}\right)$ so that it obtains a good diurnal performance. This single unit provides simultaneously

(1) the heating coil and absorbing plate;

(2) the storage tank;

(3) the glazing cover;

(4) the back-side insulation.

Besides, this concept eliminates many subsystems commonly used in solar collectors, such as

(1) the pressurizer (since the LDPE hose is able to absorb the water thermal expansion);

(2) the supporting mechanical structure;

(3) the feed and bled circuit of tank; 


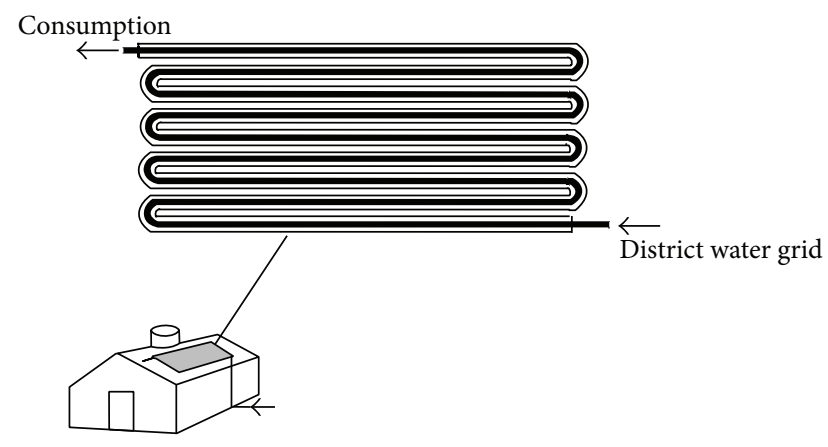

Figure 1: Schematic drawing of the hose-based solar collector.

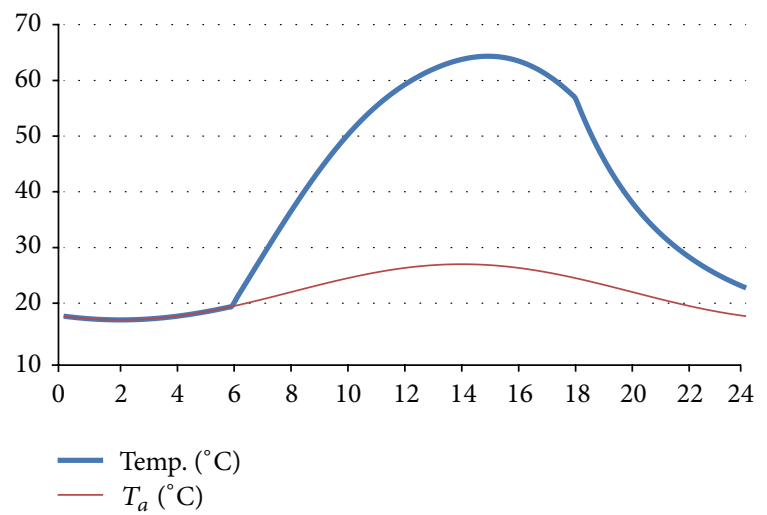

FIGURE 2: Daily evolution of a $1.5^{\prime \prime}$ hose on equinox day in Buenos Aires $\left(35^{\circ} \mathrm{S}\right)$.

(4) the air-water interface into the tank and hence the risk of bacterial disease is minimized.

Although the construction of this collector is quite simple and cheap, its right design is a challenging task that must balance the opposite behaviors, being these the diurnal and nocturnal ones as much as the summer and winter ones. For example, a too thin hose could provide fast heating during the morning but also it would be quickly cooled during the night; on the other hand, a too thick transparent insulation not only would improve the winter performance but also would lead to dangerous overheating during summers and would reduce the solar radiation received and so forth. Therefore, these coupled behaviors must be considered altogether by using a thermal-hydraulic modeling in which these linked factors are considered, so that they can be optimized by means of sensitivity analysis. Recently, this study was performed by numerical simulations supported by tests. By this way, the performance of the hose collector has been optimized for tropical locations [3] and temperate locations [4]. However, it has also been observed that this collector is not suitable for cold high-latitude locations, since its large surface causes too fast a nocturnal cooling and due to the low angle projected by sun on roofs. Instead, we are proposing now to use a hose system built by means of thick vertical tubes in order to improve both issues.

The thermal behavior along the day of the hose collector is described by its dynamic modeling, which was detailed in

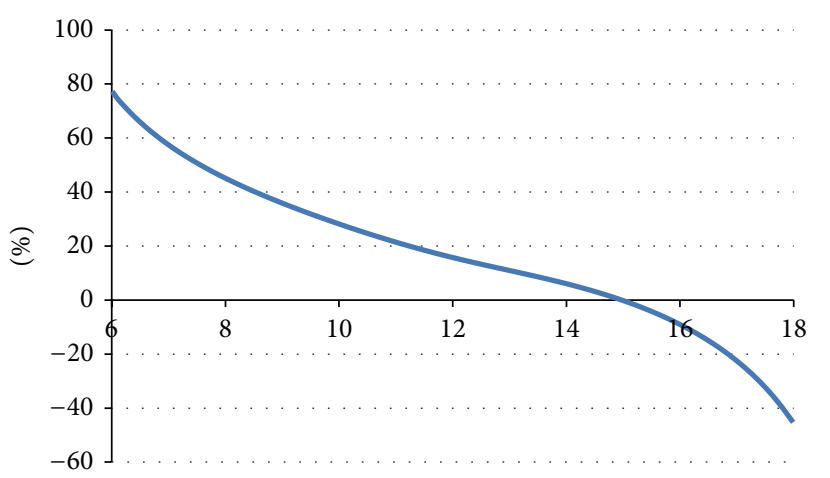

FIgURE 3: Evolution of efficiency along day for previous case.

a previous work [3]. In sum, we calculate its normal surface projected by sun in every moment of a given day and then the solar power received is estimated by approximating the solar flux $I$ as constant, which in turn is calculated from daily irradiation energy received on a horizontal surface, $E_{d}$, provided usually from solar charts. From here, the power absorbed and the heat losses terms are both considered by the efficiency equation:

$$
\mu=a_{0}-a_{1} \frac{\left(T_{m}-T_{a}\right)}{I} .
$$

The dynamic energy balance is numerically solved (by using a one-step explicit scheme) and hence the mean temperature $\left(T_{m}\right)$ along the day is calculated by using the ambient temperature $\left(T_{a}\right)$ at sunrise as initial condition [3]. Figure 2 shows the temperature evolution of a $1.5^{\prime \prime}$-diameter black hose which is double-wrapped with an air-bubble film $\left(a_{0}=\right.$ $0.80, a_{1}=14 \mathrm{~W} / \mathrm{m}^{2 \circ} \mathrm{C}$ ) [6-8] mounted over a $30^{\circ}$-inclined roof in the temperate location of Buenos Aires $\left(35^{\circ} \mathrm{S}\right)$ during the equinox-spring day $\left(T_{a}=22 \pm 5^{\circ} \mathrm{C} ; E_{d}=4.5 \mathrm{kWh} / \mathrm{m}^{2}\right)$. Here, three different behaviors can be observed.

(a) Temperature increases sharply from sunrise to noon.

(b) Temperature remains almost stationary from afternoon till sunset.

(c) Temperature decreases sharply during the night.

These three behaviors can be understood better by considering the efficiency curve that is shown in Figure 3. According to (1) the collector starts at morning with an impressive efficiency (80\%) and reaches the useful temperature $\left(35^{\circ} \mathrm{C}\right)$ at early morning $(7: 50$ a.m.) keeping still an excellent average value (60\%) along this first period. After that and according to the temperature increase, the efficiency decreases steadily up to zero during some moment in the afternoon when the collector reaches its peak of temperature. Next, the negative efficiencies observed explain the cooling up to sunset, which is stronger overnight. A negative efficiency means that heat losses exceed the solar gain collected at that moment, as it was observed during the afternoon. This behavior is common within all designs of cheap solar collectors, but their consequences are completely 
different. In this case a standard collector just stops freeconvection flow so it works similarly as a "zero-efficiency" (without gains or losses) condition, since the heated water is stored into the insulated tank. On the other hand, a waterpond collector working on negative efficiencies would suffer a cooling effect, which is determined by the same energy balance used with positive efficiencies [3].

The high efficiency observed during the morning is a key advantage that must be recognized. According to its waterpond design, which is shared with many other previous solar roofs [9-14], the mean temperature $\left(T_{m}\right)$ of the collecting system remains always equal to the temperature of the storage tank. On the other hand, a standard free-convection collector is driven by the buoyancy force caused by the temperature difference between both legs (cold and hot) of the cooling circuit, $T_{c}$ and $T_{h}$, respectively, being $T_{m}=\left(T_{h}+T_{c}\right) / 2$. Thus, a standard free-convection collector always works on a high $\left(T_{h}-T_{c}\right)$ difference (typically around $40^{\circ} \mathrm{C}$, [15-18]) that in turn implies that this collector works on a $T_{m}$ markedly higher than the storage tank or conversely having a lower efficiency than the previous design. For illustrating this key characteristic, let us consider a hose collector heated up to $30^{\circ} \mathrm{C}\left(T_{m}=30^{\circ} \mathrm{C}\right)$ working on ambient temperature, $T_{a}=$ $20^{\circ} \mathrm{C}$, so that $T_{m}-T_{a}=10^{\circ} \mathrm{C}$. On the other hand the equivalent standard collector should work on $T_{c}=30^{\circ} \mathrm{C}, T_{h}$ $=70^{\circ} \mathrm{C}$, and $T_{m}=50^{\circ} \mathrm{C}$ and thus $T_{m}-T_{a}=40^{\circ} \mathrm{C}$ that is a quadruple of the previous case. Thus, according to (1) a hose collector having the same quality (i.e., the same $a_{0}$ and $a_{1}$ values) could reach noticeably higher efficiencies than the standard collector. Although this figure cannot be quantified until the actual parameters $\left(a_{0}, a_{1}\right)$ are set, it is clear that this trend will be stronger when low-cost collectors (i.e., having higher $a_{1}$ ) are involved, as they are considered here. According to this analysis, the hose collector starts the day with impressive efficiencies, which are steadily decreasing along the morning in relation to the increasing of water temperature. On the other hand this advantage is annulled after and during the afternoon and evening and deeply during the night, when negative efficiencies and cooling effect are observed.

\section{The Vertical-Tube Collector}

According to the previous assessment and regarding the application of the hose collector to cold high-latitude locations, in this new design we are proposing attacking this weakness by several ways.

(1) By selecting a larger (around $4.5^{\prime \prime}$ ) diameter, the difference $\left(T_{m}-T_{a}\right)$ is reduced along the day and thus its efficiency is increased. By this way, the solar energy collected (per unit of surface) is higher, but it is stored in a larger water mass having a lower temperature.

(2) By selecting a vertical position and according to its cylindrical shape, the last evening rays of sun are well collected. Here we want to obtain the higher temperature at sunset rather than the maximum solar gain along the day. Since a standard collector integrates the energy gained along the day into the isolated tank, this is the suitable merit figure. But, on the other hand, the hose collector can gain or lose energy in each moment of the day and hence it is desirable to get a continuous gain along the day and to delay losses up to the night.

(3) Regarding the nocturnal losses, our present strategy adds several efforts.

(a) The heat losses are minimized by selecting a thick tube; by this way the cooling surface (per unit of mass) is minimized.

(b) Temperature decrease is minimized by selecting a thick tube; by this way the thermal inertia is enlarged since the mass stored (per unit of cooling surface) is enlarged.

(c) The heat losses are minimized by adding several insulation layers on the half-pipe back side. This technique becomes feasible here regarding the use of short straight tubes instead of long thin coiled hoses; this point will be considered in the next section.

Figures 4 and 5 illustrate better these behaviors considering the previous condition. Figure 4 shows the evolution of the previous system mounted onto horizontal and vertical roofs. Here, it is observed that the vertical hose gets a secondary peak during the evening and thus the temperature reached at sunset is noticeably higher than the horizontal hose $\left(60^{\circ} \mathrm{C}\right.$ and $41^{\circ} \mathrm{C}$, resp.). Figure 5 compares the evolution of both $1.5^{\prime \prime} 30^{\circ}$-inclined and 4.5" vertical hoses. According to our previous analysis, we can observe here that the $1.5^{\prime \prime}$ hose is heated very fast during the morning as much as it is fast cooled during the night; besides, it loses almost all the solar energy received after the noon, since its temperature at noon is around the same compared to that at sunset. On the other hand, the thick vertical tube gains energy continuously up to sunset and after that it suffers a slower cooling effect. Both trends explain why the $4.5^{\prime \prime}$ tube is a better system for satisfying a nocturnal demand instead of the previous $\left(1.5^{\prime \prime}\right)$ hose. This behavior was observed in our previous work [4], but since the maximum temperature reached by the $4.5^{\prime \prime}$ tube at sunset during a cold winter day was too low, this option was previously not considered as a good choice for colder climates [4]. However, this previous conclusion is going to be changed now by considering the improved design proposed here.

2.1. The Improved Design of the Vertical-Tube Collector. Here a new modified design feasible on thick vertical tubes is presented. As was discussed previously, this new choice is preferred for cold high-latitude locations due to their larger thermal inertia and vertical orientation. Besides the thermal insulation can be noticeably improved by adding some lowcost insulative layers on its back side (that is not exposed to solar irradiation) which in turn improves noticeably the efficiency. The vertical tube receives solar irradiation only through its north-oriented (in the south Earth's hemisphere) half pipe, but it loses energy through its whole surface. So, we study different techniques to improve the thermal insulation 


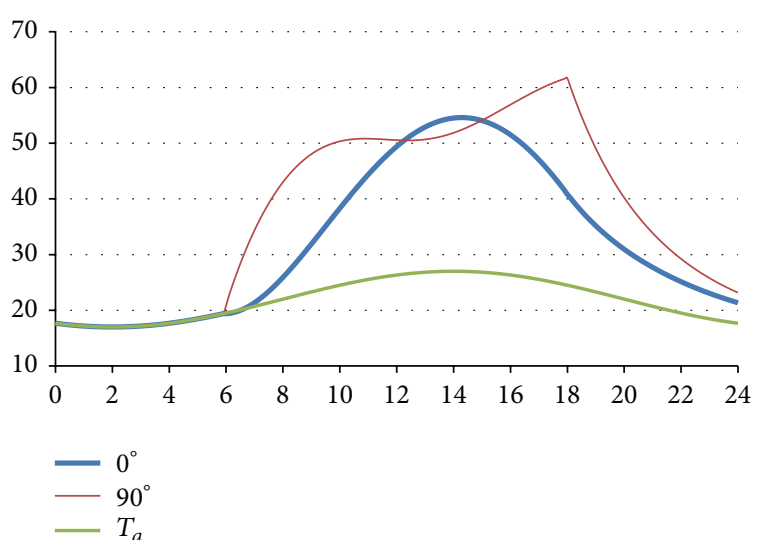

Figure 4: Evolution of vertical and horizontal $1.5^{\prime \prime}$ hoses during equinox at Buenos Aires.

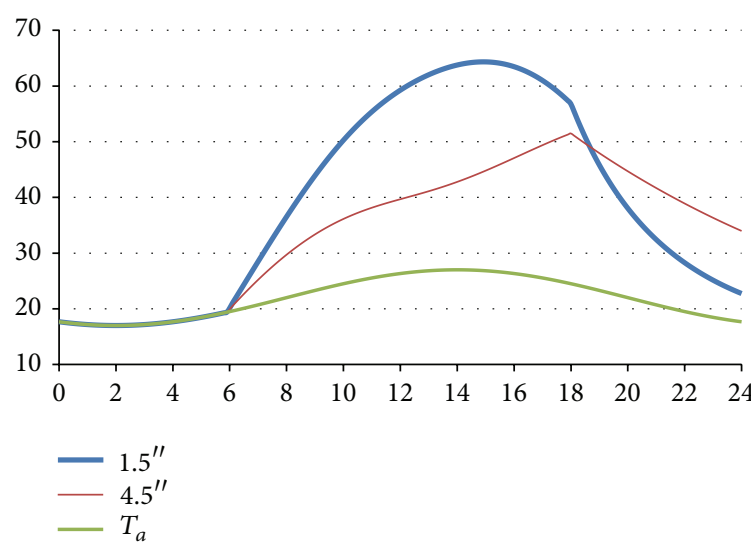

Figure 5: Evolution for vertical $4.5^{\prime \prime}$ tube and $30^{\circ}$-inclined $1.5^{\prime \prime}$ hose during equinox in Buenos Aires.

of the back half. An aluminum foil is adjusted to the wall for reducing infrared radiation and after that a nontransparent insulative layer, selected among many cheap materials like Styrofoam, polystyrene, or expanded polyurethane. These additional layers can be bound together by the same double layers previously used of air-packed polyethylene film. By this way its optical efficiency remains unalterable but its cooling is reduced to half, so $a_{0}=0.8$ and $a_{1}=7 \mathrm{~W} /{ }^{\circ} \mathrm{Cm}^{2}$ for the same double-wrapped configuration used before.

\section{Results}

3.1. Performance on a Mid-Latitude Temperate Location. Using these new parameters estimated for the improved $4.5^{\prime \prime}$ vertical collector $\left(a_{0}=0.8, a_{1}=7 \mathrm{~W} /{ }^{\circ} \mathrm{Cm}^{2}\right)$ we have recalculated its performance in Figure 6 comparing against the previous (old) design, in which is observed a noticeable improved for the new design. The peak temperature is $6^{\circ} \mathrm{C}$ higher at sunset in a winter day (July 1), but this difference increases to $10^{\circ} \mathrm{C}$ at 10 p.m., allowing the user to take a comfortable bath even five hours after sunset.

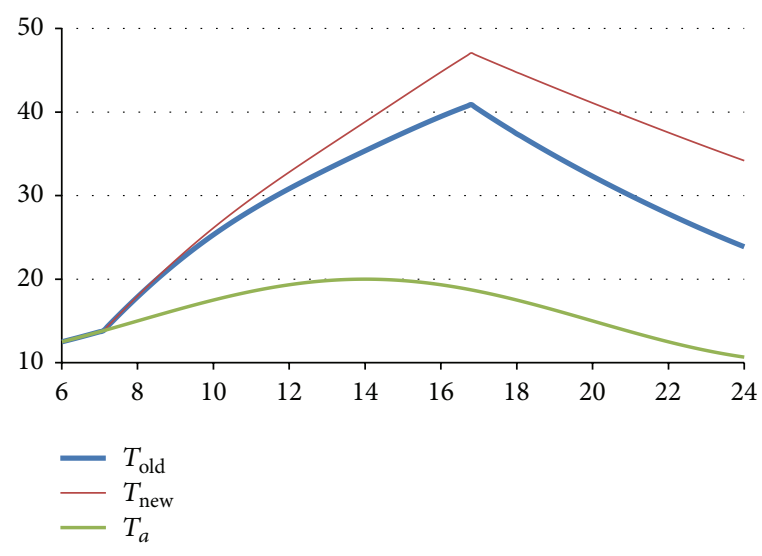

Figure 6: Improved (new) and old designs of $4.5^{\prime \prime}$ vertical tubes in winter at Buenos Aires.

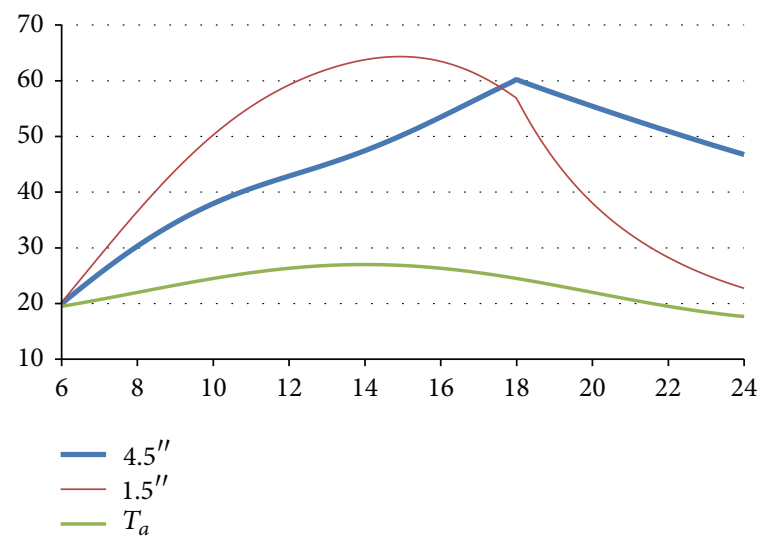

FIgURE 7: Evolution of vertical $4.5^{\prime \prime}$ new tube and $30^{\circ}$-inclined $1.5^{\prime \prime}$ hose at equinox in Buenos Aires.

This collector could be mounted on north walls and also above horizontal roofs; most of common tubes (like PVC ones) are rigid enough to keep its vertical position without an additional mechanical structure. The good results obtained make us study the performance of this novel design in higher latitudes and colder locations. Although its construction is more complex than the basic-hose collector, it is still feasible for average users considering that only a few straight tubes are used. For example a 120-liter capacity can be obtained by using a couple of $6 \mathrm{~m}$ in length $4.5^{\prime \prime}$ PVC $(2.5 \mathrm{U} \$ \mathrm{D} / \mathrm{m})$ tubes, costing about 40 dollars for the whole system. For larger systems the number of tubes increases and therefore the number of interconnections between them; a simpler and cheaper design could be obtained by using a single HDPE (1.5 $\mathrm{U} \$ \mathrm{D} / \mathrm{m}$ ) hose that is bended, for example, in vertical sections of $3 \mathrm{~m}$ tall.

Figure 7 compares the daily evolution of the new proposed system and the previous $30^{\circ}$-inclined $1.5^{\prime \prime}$ hose in Buenos Aires during the equinox day $\left(E_{d}=4.5 \mathrm{~kW} / \mathrm{m}^{2} ; T_{a}=\right.$ $\left.22^{\circ} \mathrm{C} \pm 5^{\circ} \mathrm{C}[5]\right)$. We can observe the excellent performance of this new system that provides warm water along the whole night. On the contrary, the $1.5^{\prime \prime}$ basic hose provides hot 


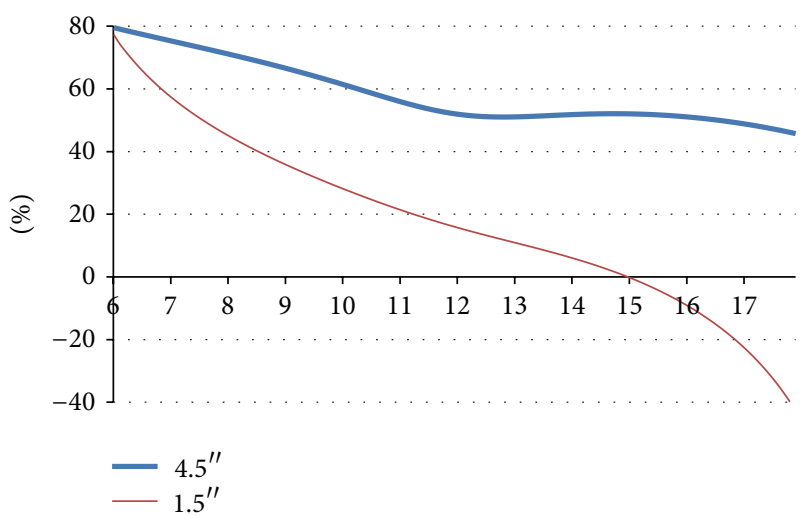

FIGURE 8: Evolution of efficiency for both previous systems at Buenos Aires.

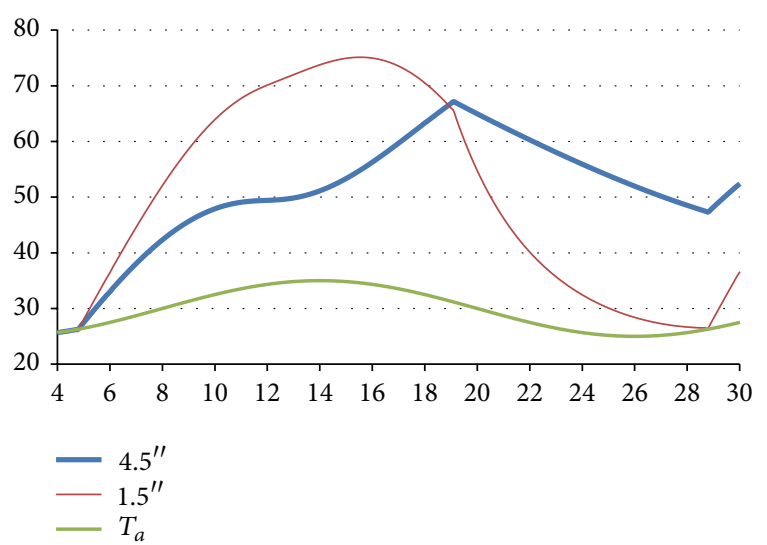

FIGURE 9: Temperature evolution for both systems during summer at Buenos Aires.

water only four hours after sunset. Besides, according to our previous hypothesis, we observe that the average daily efficiency (from sunrise till sunset) of the new system is $58 \%$, against $17 \%$ of the $1.5^{\prime \prime}$ hose; both behaviors are better illustrated in Figure 8. Here, it is interesting to note that the $1.5^{\prime \prime}$ hose cannot keep the energy absorbed after 11 a.m., since the temperature at sunset $\left(55^{\circ} \mathrm{C}\right)$ is the same compared to at 11 a.m. (see Figure 7). On the other hand, the vertical thick tube can store the energy collected along the whole day. In Figure 8 a valley peak around the noon is observed due to the high inclination of the sun rays relative to the vertical tube at that moment or conversely the higher efficiency observed during the afternoon for the opposite cause. This last trend is a key to get good performance in high-latitude locations, as we will study next.

Figure 9 shows the temperature evolution of both systems for the hot season (January $1 ; E_{d}=6.5 \mathrm{kWh} / \mathrm{m}^{2}, T_{a}=30^{\circ} \mathrm{C}$ $\left.\pm 5^{\circ} \mathrm{C}[5]\right)$. Let us note the dangerous peak $\left(76^{\circ} \mathrm{C}\right)$ reached by the $1.5^{\prime \prime}$ hose that otherwise cannot provide hot water during the whole night. On the other hand the thick tube varies slowly during the whole cycle having not so high temperatures. Let us note that its minimum at sunrise is noticeably higher than at ambient, $T_{a}$; therefore this system
TABLE 1: Parameters for the cold-climate location of Ushuaia $\left(55^{\circ} \mathrm{S}\right)$ [5].

\begin{tabular}{lccc}
\hline Date/season & $G^{\prime \prime}\left(\mathrm{kWh} / \mathrm{m}^{2}\right)$ & $I\left(\mathrm{~W} / \mathrm{m}^{2}\right)$ & $T_{a}\left({ }^{\circ} \mathrm{C}\right)$ \\
\hline January 1/summer & 5.5 & 580 & $14 \pm 8$ \\
March 21/fall & 2.5 & 570 & $5 \pm 5$ \\
July 1/winter & 0.5 & 530 & $-2 \pm 4$ \\
\hline
\end{tabular}

can store energy from one day to another. This new trend (observed during the equinox too; see Figure 7) allows it to keep better performance on cloudy days.

3.2. Performance on a High-Latitude Cold Location. Table 1 presents the climatic parameter of the southernmost $\left(-55^{\circ} \mathrm{S}\right)$ Argentinean city of Ushuaia, which has a maritime cold climate. For this case, the basic-hose collector is not recommended (beyond the snowing winters that forbids to mount it onto the roof), due to the poor (even negative) performances obtained during most parts of the year, as Figure 10 shows. The nocturnal demand cannot be satisfied almost never along the year, although it could be considered as a useful preheater during the day during half year. On the other hand, the new $4.5^{\prime \prime}$ vertical system (see Figure 11) extends the preheater period (including its nocturnal utilization) to the whole year, and also it could satisfy completely the household demand during summer. The choice of vertical position and cylindrical shape explains this outstanding performance, since it receives during winter seven times more solar radiation than a flat horizontal collecting surface. Furthermore, this novel design can be optimized for this case by performing the sensitivity analysis of the tube diameter and numbers of wrapping layers. The study of diameter is reflected in Figure 12, showing that a $3^{\prime \prime}$ tube allows us to improve both the diurnal and nocturnal performances along the whole year. The study of wrapping layers is reflected in Figure 13 for the $3^{\prime \prime}$ tube, showing that a triple wrapping obtains the maximum peak temperature; meanwhile the quadruple wrapping gets the best nocturnal performance.

\section{Conclusions}

This paper presents a new design of solar collector based in large-diameter plastic hoses connected directly to consumption. This design follows the old concept of water ponds used in many solar collectors, whose particular thermal characteristics are being often ignored. For example, while a standard collector is optimized by its total daily gain and its nocturnal losses are negligible, the hose collector must balance its diurnal and nocturnal behaviors, being both noticeable and coupled.

Both pairs of opposite behaviors found (diurnal and nocturnal, winter and summer) have been discussed for different cold climates by numerical simulation. It has been demonstrated for mid-latitude temperate locations that by using thicker tubes (4.5" against $1.5^{\prime \prime}$ on previous works) higher total daily efficiencies are obtained since a thick system can steadily gain energy till sunset whereas thinner hoses 


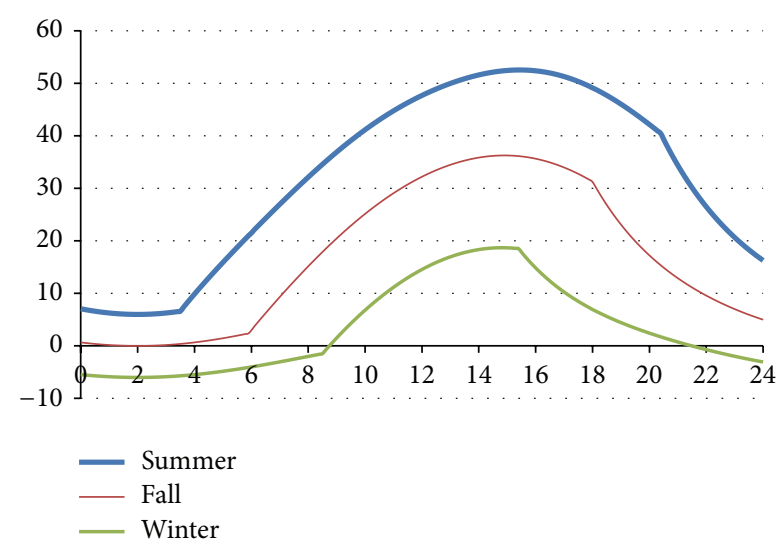

FIGURE 10: Annual performance of the $1.5^{\prime \prime} 30^{\circ}$-inclined hose collector in Ushuaia.

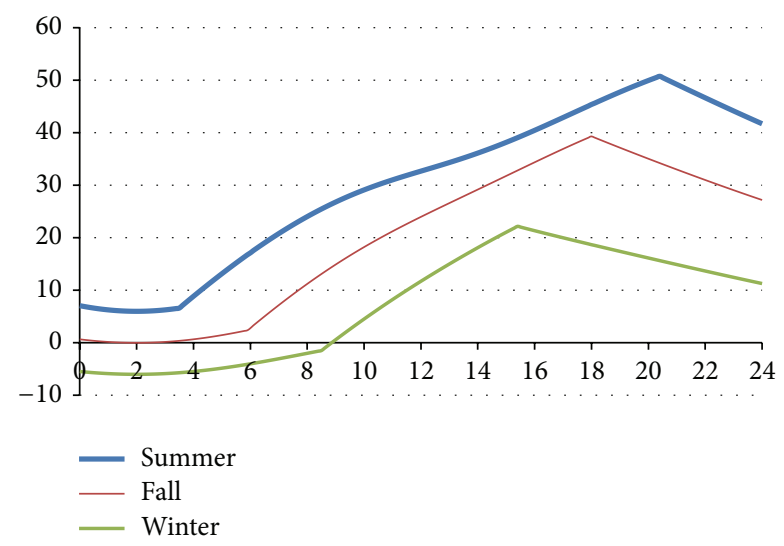

FIgURE 11: Annual performance of the new $4.5^{\prime \prime}$ collector at Ushuaia.

cannot do it after noon, which is a key problem. Besides, a thicker tube reduces nocturnal cooling by increasing its thermal inertia and, in addition, the use of vertical tubes allows us to improve noticeably its solar area projected during the evenings, a key factor for cold climates and high latitudes.

The results show that the new collector could fully provide the nocturnal demand (up midnight) of hot sanitary water along the whole year for a temperate mid-latitude location (Buenos Aires, $35^{\circ} \mathrm{S}$ ) whereas the previous hose design could barely satisfy it during summers. This improvement is explained by both the noticeable increasing of daily efficiency ( $58 \%$ to $17 \%$ ) and the decreasing of nocturnal cooling, both being related to the vertical shape and thicker tubes selected. In addition, it has been observed that these trends are stronger as colder climates and higher latitudes are considered. For a high-latitude maritime-climate location $\left(55^{\circ} \mathrm{S}\right)$, this new collector could provide enough hot water in summers and also it could be a useful preheater along the whole year whereas the previous hose design could barely satisfy the diurnal demand in summers. Finally, the sensitivity analysis has demonstrated that the collector can be optimized noticeably for a given particular condition, by

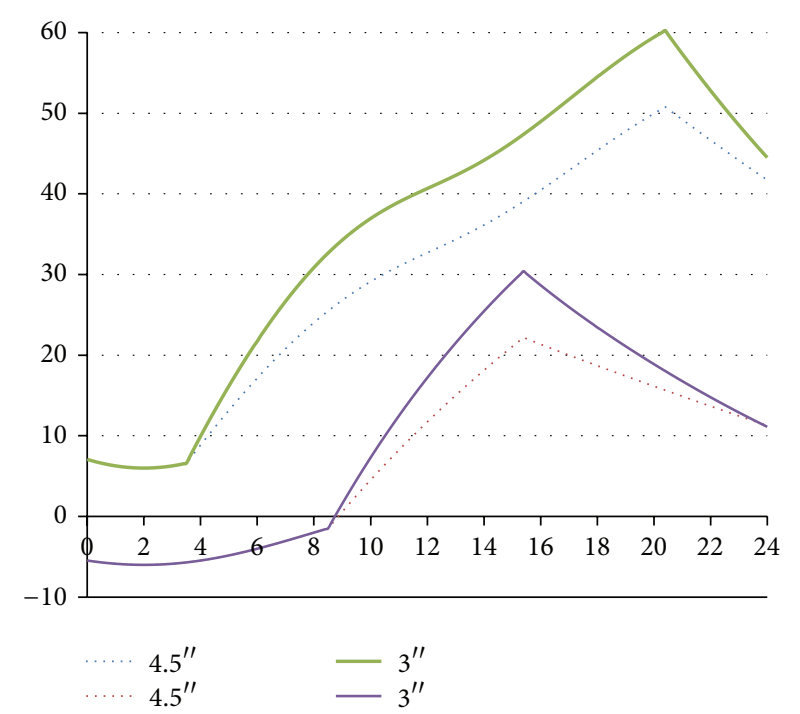

FIGURE 12: Summer and winter performances for the new $4.5^{\prime \prime}$ and $3^{\prime \prime}$ collectors at Ushuaia.
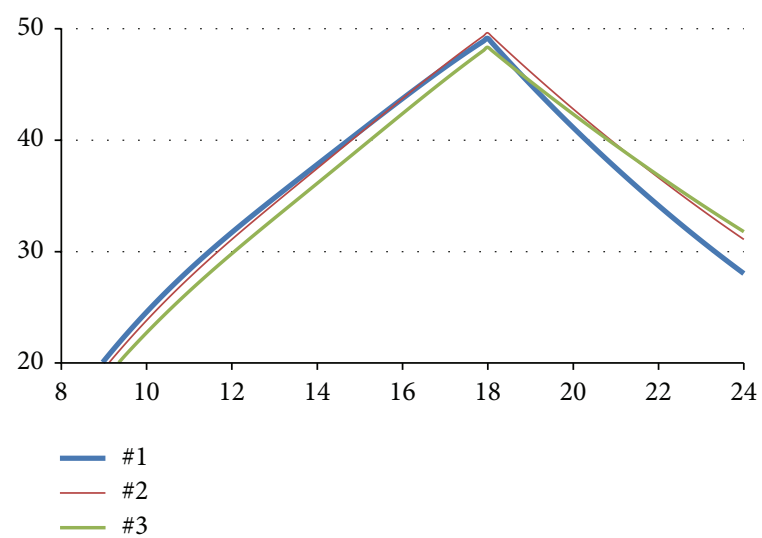

FIGURE 13: Temperature evolution in equinox day of the vertical $3^{\prime \prime}$ tube with wrapping layers: \#1, double; \#2, triple; \#3, quadruple, at Ushuaia.

considering parameters such as tube diameter and number of glazing layers.

Although it is necessary to perform field tests in order to get accuracy predictions, the high simplicity and flexibility of this water-pond collector allow the user to do it himself. For example, by testing just a few short tubes, the user can optimize and calculate the performance of large collectors. Regarding this point, this collector shows an advantage over free-convection collectors, in which its performance cannot be scaled up directly from small prototypes.

\section{Conflict of Interests}

The authors declare that there is no conflict of interests regarding the publication of this paper. 


\section{Acknowledgments}

Argentinian Du Pont Enterprise is acknowledged for its support by funds given through the National Prize Du Pont to Clean Energies 2009 to this project.

\section{References}

[1] P. T. Tsilingiris, "Towards making solar water heating technology feasible-the polymer solar collector approach," Energy Conversion and Management, vol. 40, no. 12, pp. 1237-1250, 1999.

[2] A. M. Papadopoulos, "State of the art in thermal insulation materials and aims for future developments," Energy and Buildings, vol. 37, no. 1, pp. 77-86, 2005.

[3] L. E. Juanicó and N. Di Lalla, "A new low-cost plastic solar collector," ISRN Renewable Energy, vol. 2013, Article ID 102947, 10 pages, 2013.

[4] L. Juanicó and N. Dilalla, "Optimization of the hose-based lowcost solar collector," International Journal of Renewable Energy \& Biofuels, vol. 2014, Article ID 344621, 13 pages, 2014.

[5] R. Righini, H. G. Gallegos, and C. Raichijk, "Approach to drawing new global solar irradiation contour maps for Argentina," Renewable Energy, vol. 30, no. 8, pp. 1241-1255, 2005.

[6] G. M. Wallner, W. Platzer, and R. W. Lang, "Structure-property correlations of polymeric films for transparent insulation wall applications. Part 1. Solar optical properties," Solar Energy, vol. 79, no. 6, pp. 583-592, 2005.

[7] G. M. Wallner, W. Platzer, and R. W. Lang, "Structure-property correlations of polymeric films for transparent insulation wall applications. Part 2: Infrared optical properties," Solar Energy, vol. 79, no. 6, pp. 593-602, 2005.

[8] G. M. Wallner, R. Hausner, H. Hegedys, H. Schobermayr, and R. W. Lang, "Application demonstration and performance of a cellulose triacetate polymer film based transparent insulation wall heating system," Solar Energy, vol. 80, no. 11, pp. 1410-1416, 2006.

[9] H. R. Hay and J. I. Yellott, "International aspects of air conditioning with movable insulation," Solar Energy, vol. 12, no. 4, pp. 427-438, 1969.

[10] M. Hawlader and B. Brinkworth, "An analysis of the nonconvecting solar pond," Solar Energy, vol. 27, no. 3, pp. 195-204, 1981.

[11] L. Juanicó, "A new design of roof-integrated water solar collector for domestic heating and cooling," Solar Energy, vol. 82, no. 6, pp. 481-492, 2008.

[12] L. E. Juanicó, "New design of solar roof for household heating and cooling," International Journal of Hydrogen Energy, vol. 35, no. 11, pp. 5823-5826, 2010.

[13] I. Bozkurt and M. Karakilcik, "The daily performance of a solar pond integrated with solar collectors," Solar Energy, vol. 86, no. 5, pp. 1611-1620, 2012.

[14] M. N. A. Hawlader and B. J. Brinkworth, "An analysis of the non-convecting solar pond," Solar Energy, vol. 27, no. 3, pp. 195204, 1981.

[15] J. K. Nayak and E. H. Amer, "Experimental and theoretical evaluation of dynamic test procedures for solar flat-plate collectors," Solar Energy, vol. 69, no. 5, pp. 377-401, 2000.

[16] T. Osório and M. Carvalho, "Testing of solar thermal collectors under transient conditions," Solar Energy, vol. 104, pp. 71-81, 2014.
[17] D. Carbonell, J. Cadafalch, and R. Consul, "Dynamic modelling of flat plate solar collectors: analysis and validation under thermosyphon conditions," Solar Energy, vol. 89, pp. 100-112, 2013.

[18] E. Aranovitch, "Heat transfer processes in solar collectors," Energy and Buildings, vol. 3, no. 1, pp. 31-47, 1981. 


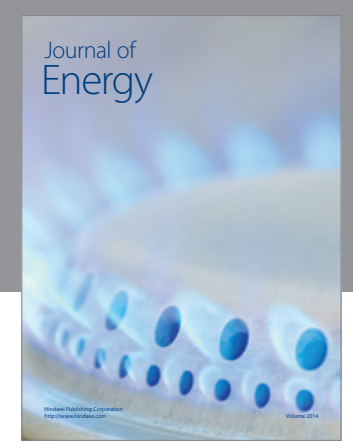

Journal of

Industrial Engineering
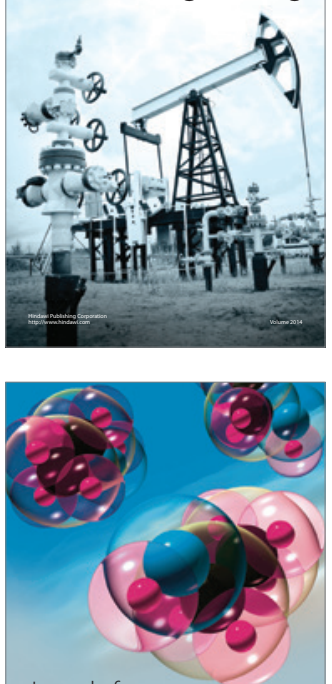

Fuels
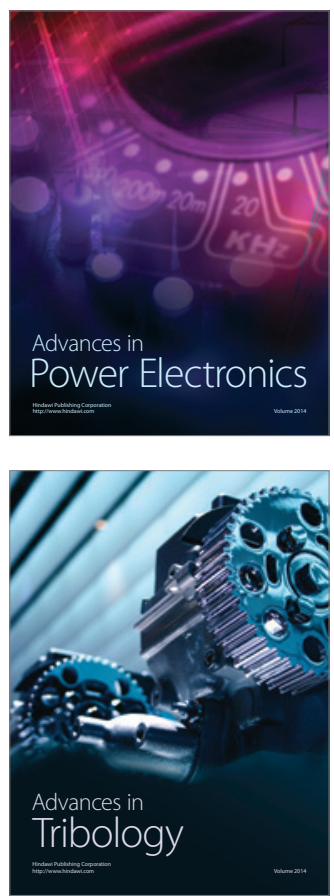

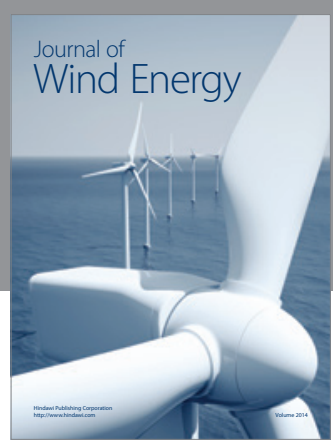

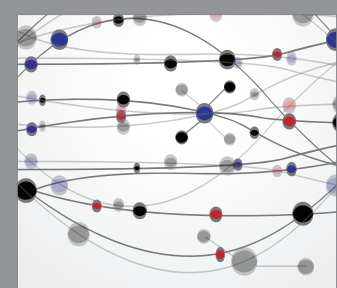

The Scientific World Journal

Submit your manuscripts at http://www.hindawi.com

Journal of

Structures
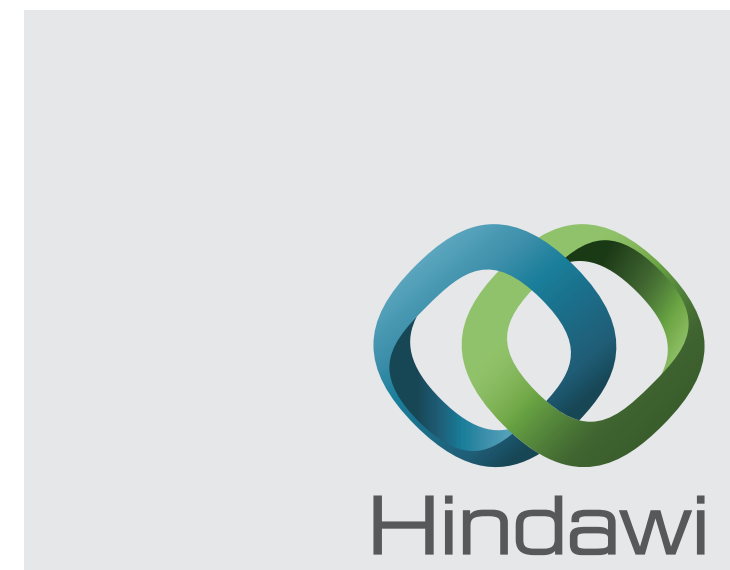

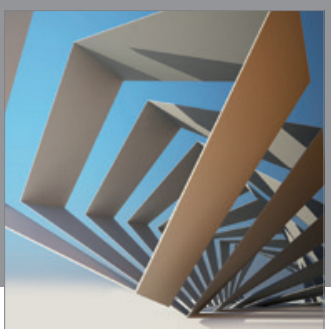

Rotating

Machinery
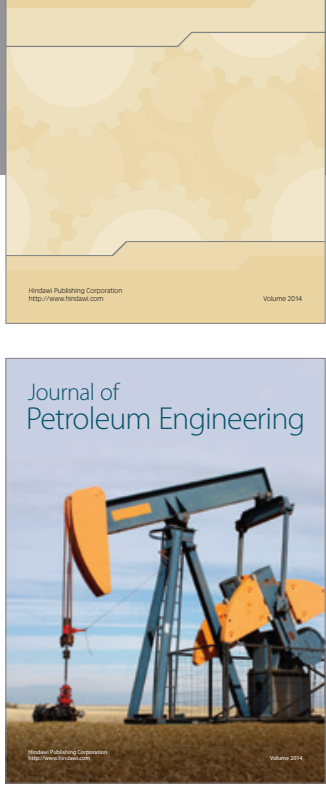

Journal of

Solar Energy
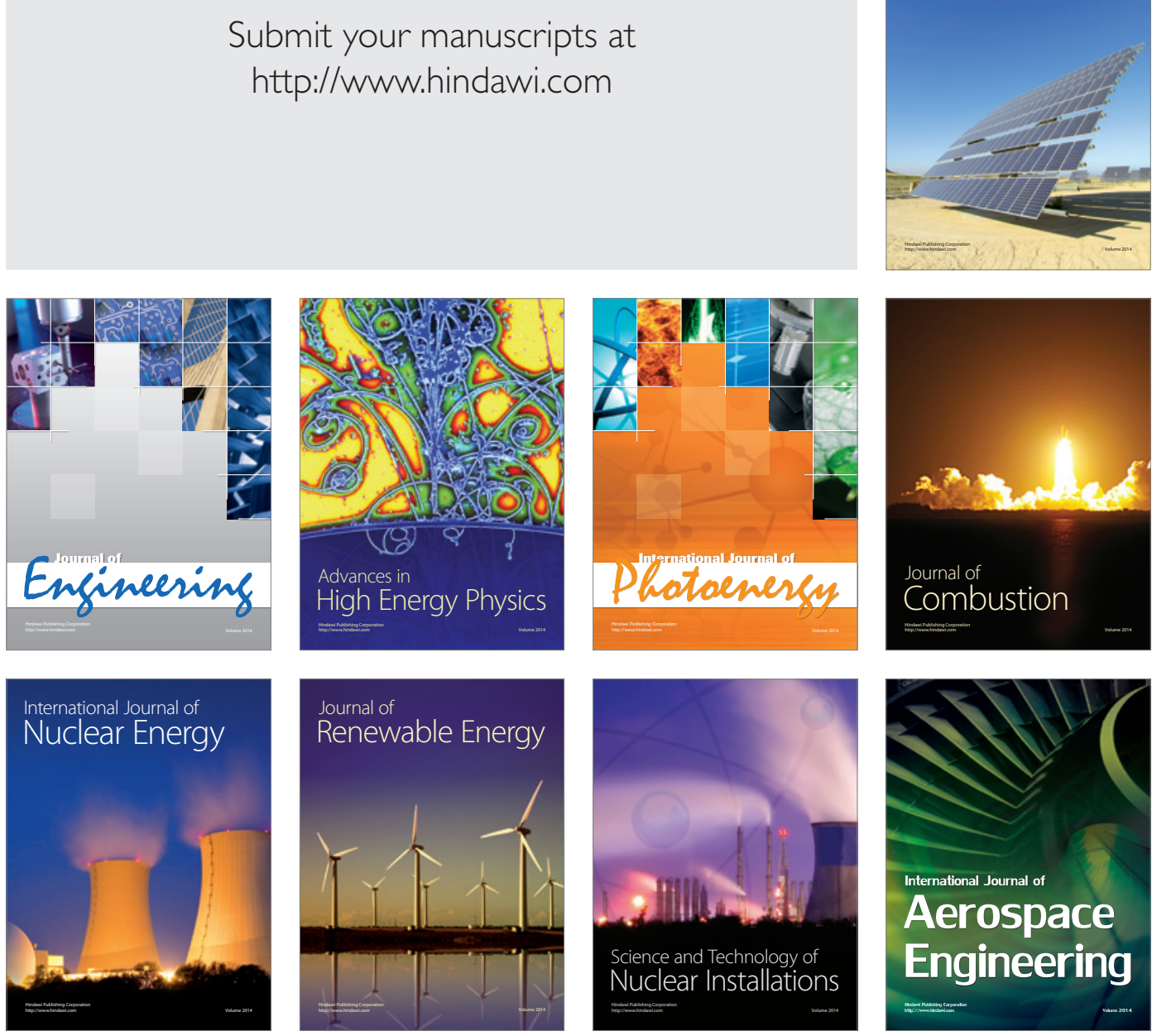